\title{
Prospecção Tecnológica do Lúpulo (Humulus Iupulus L.) e suas Aplicações com Ênfase no Mercado Cervejeiro Brasileiro
}

\author{
Technological Prospection of Hop (Humulus lupulus L.) and its \\ Applications with Emphasis in the Brazilian Brewing Market
}

\author{
Bernardo Pontes Guimarães ${ }^{1}$ \\ Rafael Benjamin Werneburg Evaristo ${ }^{1}$ \\ Grace Ferreira Ghesti ${ }^{1}$ \\ ${ }^{1}$ Universidade de Brasília, Brasilia, DF, Brasil
}

\begin{abstract}
Resumo
O lúpulo é o insumo utilizado na fabricação de cerveja responsável por aromas e pelo amargor da bebida. No Brasil, essa matéria-prima é importada quase que em sua totalidade. Essa planta, habituada a regiões de clima específico, está sendo cultivada em solo brasileiro e obtendo resultados promissores. Em função disso, o presente artigo buscou realizar uma prospecção tecnológica, por meio de uma metodologia qualitativa exploratória, sobre o que está sendo estudado e desenvolvido sobre lúpulo e sua utilização no processo cervejeiro nos últimos 20 anos. Sabe-se que, a partir do momento em que houver a comercialização de lúpulo nacional, novas tecnologias e processos serão necessários para sua manufatura. A pesquisa revelou uma tendência de países com maior produção de lúpulo ou cerveja a investirem mais em pesquisa e desenvolvimento no setor. Além do mais, foram identificados entraves para a inserção apropriada do lúpulo cultivado em território nacional para ser utilizado pelas cervejarias.
\end{abstract}

Palavras-chaves: Lúpulo. Indústria Cervejeira. Prospecção Tecnológica.

\begin{abstract}
Hops are the ingredient used in beer brewing responsible for aromas and bitterness in the beverage. In Brazil it is almost entirely imported. This plant, although used to specific climate regions, has been cultivated in Brazilian soil and has obtained promising results. In light of this, this paper did a technological prospection on what has been researched and developed on hops and their utilization in the brewing process for the last 20 years. It is known that from the moment that Brazilian hops begun to be commercialized; new technologies and processes are required for their proper use. This research showed that the countries with highest beer or hops production invested more in the research and development sector. Other findings of this study included the difficulties for the appropriate insertion of hops cultivated in Brazilian territory to be used by breweries.
\end{abstract}

Keywords: Hops. Brewing Industry. Technological Prospecting.

Área Tecnológica: Lúpulo. Indústria de Alimentos. Mercado Cervejeiro. 


\section{Introdução}

O lúpulo (Humulus lupulus L.) é uma planta com florescência anual que é cultivado em países de clima temperado, em especial entre os paralelos 35 e 55 dos Hemisférios Norte e Sul (BOCQUET et al., 2018), ilustrado pela Figura 1. Embora haja tentativas de cultivo em regiões tropicais também, como no Brasil (MARCUSSO; MÜLLER, 2019).

Figura 1 - Mapa-Múndi com os principais países produtores de lúpulo em verde e as áreas compreendidas em amarelo

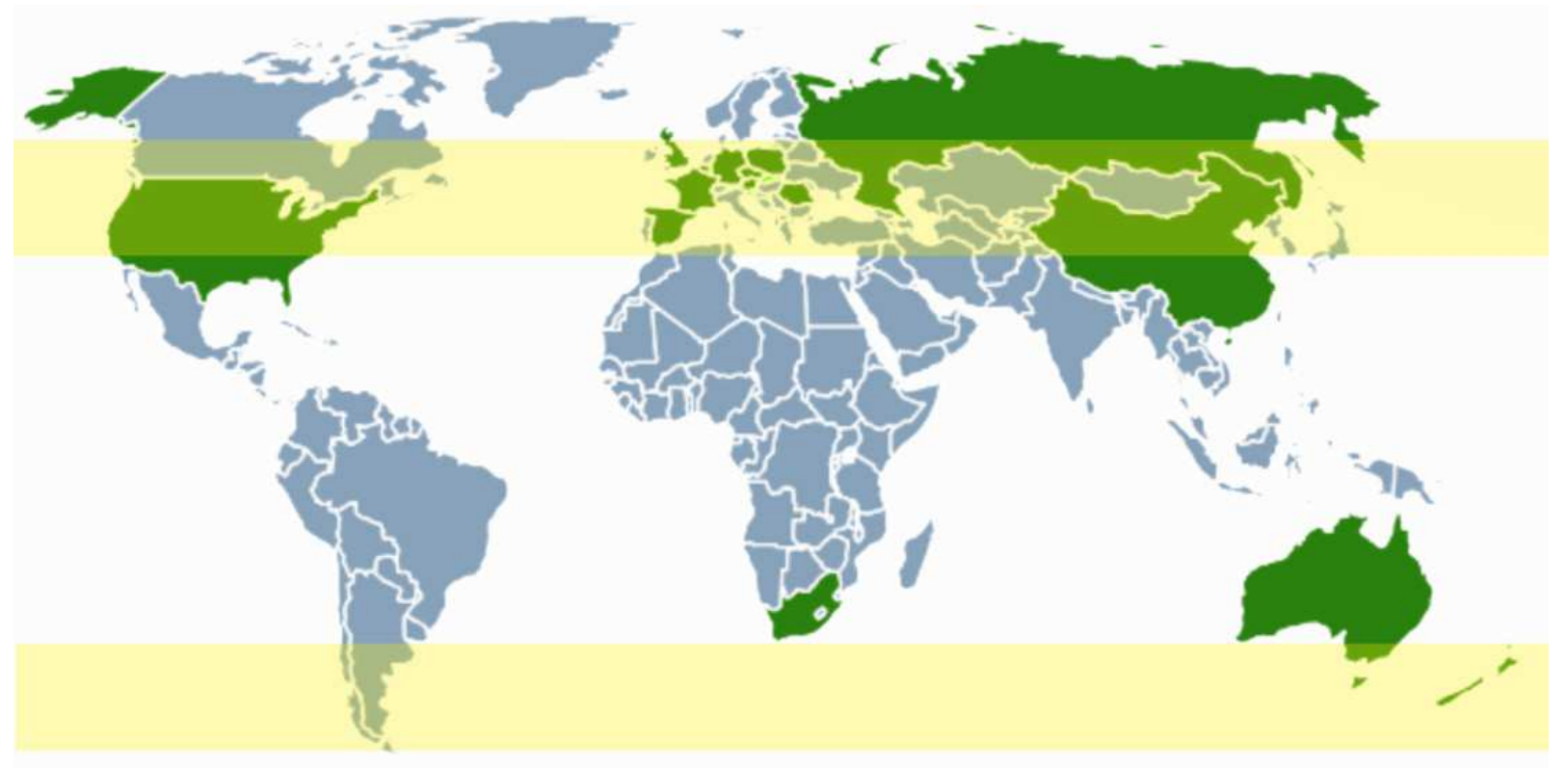

Fonte: Elaborada pelos autores deste artigo (2019)

Na flor da planta fêmea, encontra-se a glândula de lupulina, onde se localizam os componentes de maior interesse do lúpulo, os $\alpha$-ácidos, $\beta$-ácidos, polifenóis e óleos essenciais (CATTOOR et al., 2013). Essa inflorescência é mundialmente conhecida como elemento de grande importância no processo cervejeiro, fornecendo aroma, sabor e amargor à cerveja, além de evitar sua contaminação por bactérias (VOLLMER et al., 2018; YAN et al., 2018).

Os Estados Unidos e a Alemanha são os dois maiores produtores de lúpulo, sendo produzidas 48.191 e 41.556 toneladas anualmente, respectivamente (IHGC, 2018). Embora o lúpulo e seus derivados atendam a uma diversidade de produtos que passam desde a indústria farmacêutica até a alimentícia, sua produção se destaca no atendimento ao setor cervejeiro, sendo esse um dos integrantes elementares para formulação de cerveja, assim como a água, o malte de cevada e a levedura.

O Brasil é o terceiro maior produtor de cerveja no mundo (CARVALHO et al., 2018) com 15,3 bilhões de litros produzidos em 2018 (IBGE, 2020). Esse grande volume de cerveja requer grandes quantidades de insumo, sendo os principais: malte de cevada e lúpulo, deste, pelo menos 98\% do produto é importado (BERBERT, 2017).

O cenário da produção de lúpulo no Brasil se encontra de forma muito incipiente devido às especificidades regionais brasileiras que não favorecem o cultivo da planta nas mesmas condições de países com clima temperado. Desde 2005, há registro de tentativas de cultivo de 
lúpulo no País, embora tenha sido observado o desenvolvimento da planta somente em 2011, impulsionando seu cultivo. $\mathrm{O}$ interesse no cultivo em solo brasileiro tem aumentado com influência de tecnologias adaptadas ou pela própria manipulação da espécie via cruzamento para melhoramento genético e possibilidade de adaptação às condições locais (BRASIL, 2018). Essa escalada de interesse, tanto no cultivo quanto na exploração comercial do lúpulo, tem atraído investimentos importantes para seu estabelecimento no cenário nacional, como é o caso do Banco do Brasil em parceira com o Estado do Rio de Janeiro, abrindo uma linha de crédito de $\mathrm{R} \$ 600$ milhões para cultivo da planta, impulsionando não apenas o setor agrícola como também a indústria e o turismo cervejeiro (presente fortemente na região serrana do Estado) (FREITAS, 2019). Mesmo que de forma inicial, e ainda em fase de desenvolvimento, a produção de lúpulo tem interessado alguns produtores agrícolas no País, localizados principalmente nas Regiões Sul e Sudeste.

Dessa forma, este trabalho tem como objetivo estudar o panorama do ponto de vista da produção científica, tecnológica e mercadológica do lúpulo, sendo esse produto de relevância mundial no que diz respeito à produção de cerveja. Além disso, busca-se fomentar a relevância do lúpulo no mercado brasileiro, aliando cultivo, tecnologia e diversificação da matéria-prima. Pensando não somente no produto ao qual é aplicado, mas também no impacto que sua exploração em nível nacional pode acarretar para o setor cervejeiro.

\section{Metodologia}

Foi realizado o estudo de prospecção tecnológica acerca das tecnologias envolvendo o lúpulo e suas principais aplicações, em especial no processo cervejeiro, a partir de dados coletados em bases de patentes, artigos científicos e avaliação dos produtos comercializados na área. As buscas de artigos científicos foram realizadas pelo sítio Web of Science (base que abrange mais de 20.000 periódicos) (CLARIVATE ANALYTICS, 2017), restringindo-se aos artigos publicados nos últimos 20 anos, de 2000 a 2019. Já a busca por patentes foi realizada na plataforma Questel Orbit Intelligence (ORBIT®).

Para a busca de artigos científicos, utilizou-se o campo de pesquisa "Título ou Resumo" e as palavras-chaves em inglês: lúpulo (hop OR hops), cerveja (beer), e bebida (beverage OR drink). As palavras-chaves utilizadas foram combinadas com operadores booleanos da seguinte forma: "(hop OR hops)", "(hop OR hops) AND beer)", "((hop OR hops) AND (beverage OR drink))". A estratégia de buscas por patentes foi semelhante à da busca realizada para os artigos científicos, mas a delimitação temporal foi data de depósito entre 2000 e 2019.

As buscas foram realizadas durante o mês de agosto de 2020, e a análise dos dados considerou os seguintes indicadores no que se refere aos dados patentários: número de depósitos por ano, países com maior número de depósitos, empresas/instituições que mais depositaram e domínio tecnológico. Além disso, foram analisados os códigos predominantes para o conjunto de termos buscados por meio da Classificação Internacional de Patentes (CIP). Já para os artigos científicos, os seguintes indicadores foram considerados: quantidade de artigos publicados por ano, países que mais publicaram, instituições que mais publicaram e área de pesquisa. 


\section{Resultados e Discussão}

Tomando como base a prospecção tecnológica em base de patentes (Tabela 1), observou-se um grande número de patentes utilizando os termos "hop OR hops" (38.590) e uma quantidade bem menor quando combinado com outros termos (1.733 e 742). Com base nos documentos encontrados, observa-se que o termo "hop" pode ser utilizado com referência ao lúpulo, mas também com referência a outros termos (uma vez que pode ser utilizado como verbo ou substantivo) que remetem a tecnologias outras que fogem ao escopo deste estudo.

Ao restringir a busca à aplicação em bebidas e cervejas, verificou-se uma predominância de patentes em comparação à produção de artigos. Esse fato é explicado pelo grande interesse comercial e pela aplicação industrial sobre as tecnologias desenvolvidas, além do fato de a indústria anteceder a pesquisa.

Tabela 1 - Pesquisa de patentes utilizando o Orbit e artigos científicos utilizando o sítio Web of Science no período de 2000 a 2019 com as palavras-chaves selecionadas

\begin{tabular}{ccccc} 
Palavra-chave & Operador & Palavra-chave & $\begin{array}{c}\text { Resultado busca } \\
\text { por patentes }\end{array}$ & $\begin{array}{c}\text { Resultado busca } \\
\text { por artigos }\end{array}$ \\
\hline $\begin{array}{c}\text { (hop OR hops) } \\
\text { (hop OR hops) }\end{array}$ & AND & - & 38.590 & 73.968 \\
(hop OR hops) & AND & beer & 1.733 & 1.060 \\
$\begin{array}{c}\text { (hop OR hops) } \\
\text { AND (beer) }\end{array}$ & OR & $\begin{array}{c}\text { (hop OR hops) AND } \\
\text { (beverage OR drink) }\end{array}$ & 742 & 205 \\
\hline
\end{tabular}

Fonte: Orbit (2020) e Web of Science (2020)

A Figura 2 apresenta o número de patentes depositadas por ano de publicação para as combinações dos termos 2 e 3 da Tabela 1, com 2.225 resultados. Observou-se um pequeno aumento ao longo dos anos do número de patentes nos últimos 20 anos. A variação destoante no número de patentes em 2010 e 2011 é resultado expressado pelo depósito de um único inventor russo, o Kvasenkov Oleg Ivanovich, apresentando 761 pedidos de patentes com as palavras-chaves deste artigo no período de 2000 a 2019. As patentes apresentadas nesses anos possuem a mesma data de depósito e não foram avaliadas até o momento desta pesquisa. Os documentos em questão são receitas e possuem o mesmo título, processo de fabricação de cerveja escura (Production method of flavoured dark beer, em inglês), e, em suas descrições dos resumos, há a substituição do insumo adicionado ao processo, sendo que alguns exemplos foram: nozes, sucos, frutas, temperos, etc. Essas patentes não possuem relevância no que se refere a esta pesquisa, ou seja, não estão diretamente relacionadas ao lúpulo (apenas são citados os termos, tendo em vista que o lúpulo é elemento fundamental para a fabricação de qualquer cerveja). Esse tipo de documento (receitas) não atende aos requisitos de patenteabilidade brasileira, porém pode atender à legislação dos países nos quais foram depositadas. Portanto, os resultados desta pesquisa excluem as patentes do referido autor, totalizando 1.464 patentes depositadas. 
Figura 2 - Número de famílias de patentes depositadas por ano de publicação entre 2000 e 2019 com as palavras-chave ((hop OR hops) AND beer) OR ((hop OR hops) AND (beverage OR drink)) sem (em preto) e com (em cinza) o inventor Kvasenkov Oleg Ivanovich

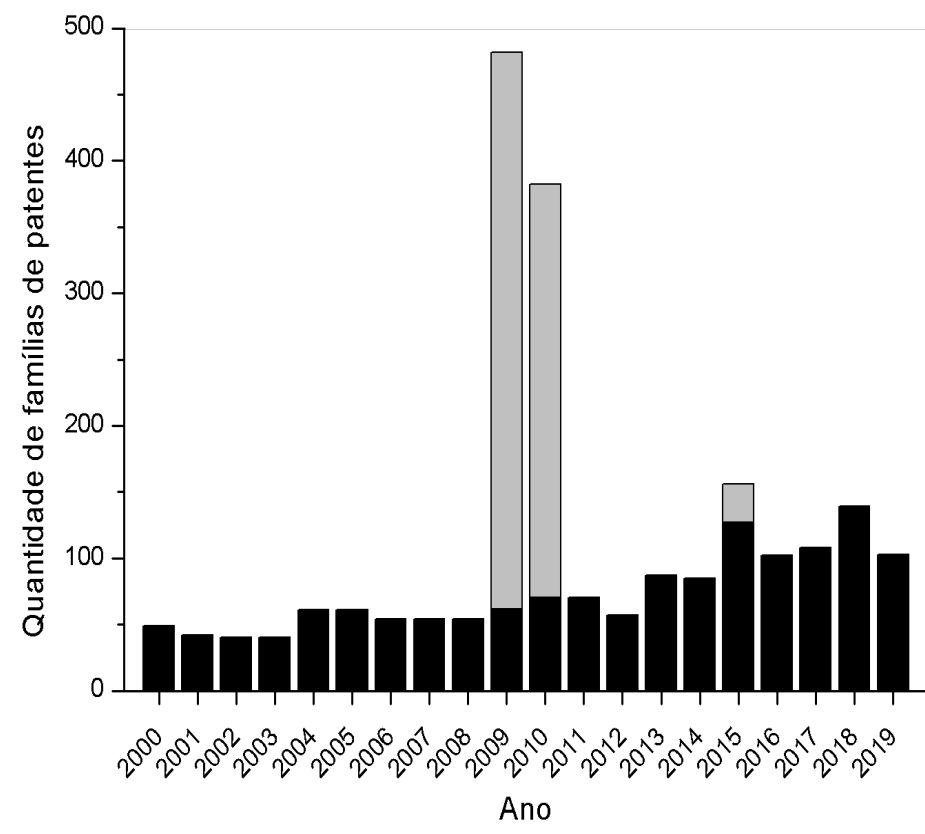

Fonte: Orbit (2020)

Figura 3 - Países que mais depositaram patentes no período de 2000 a 2019 com as palavras-chave ((hop OR hops) AND beer) OR ((hop OR hops) AND (beverage OR drink)) e sem o inventor Kvasenkov Oleg Ivanovich

Publication country

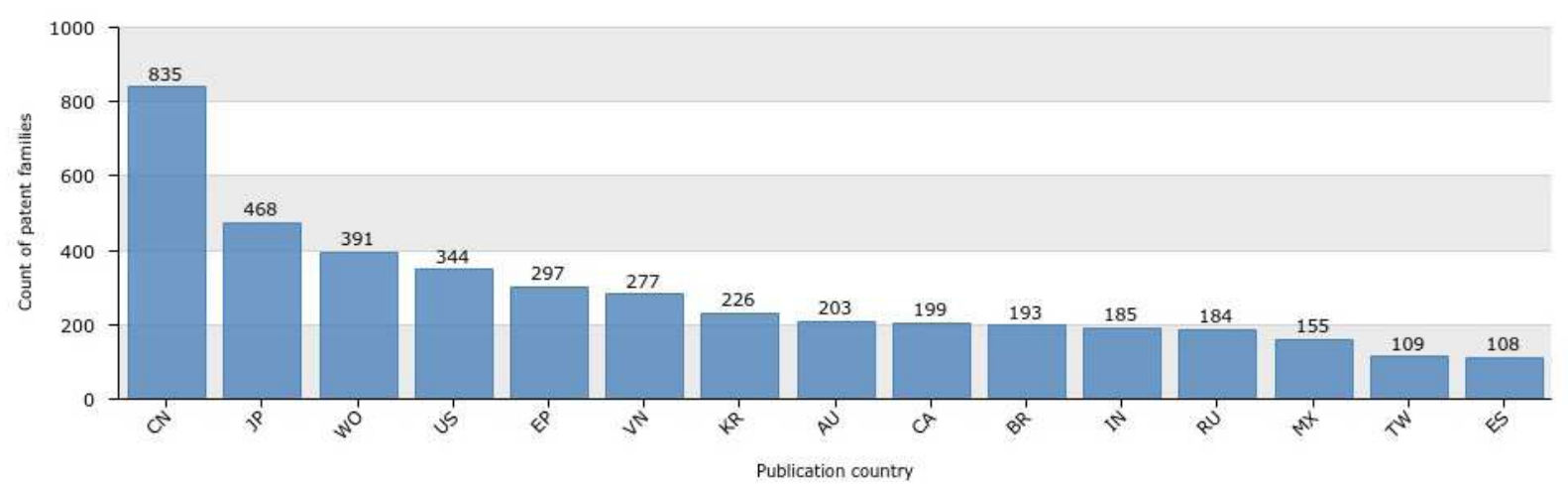

Fonte: Orbit (2020)

Desconsiderando os documentos de Kvasenkov Oleg Ivanovich, os países com número de patentes superior ao mundial são: China e Japão (Figura 3). Os números da China (835 patentes depositadas) refletem a maior produção de cerveja mundial, com as terceira, sexta e oitava maiores empresas do ramo cervejeiro, resultado de sua legislação e de políticas públicas relacionadas à propriedade intelectual do país (OLIVEIRA et al., 2018). Já o Japão está representado pelas empresas Asahi Breweries e Kirin, que ocupam as sétima e nona posições, respectivamente, das maiores cervejarias e possui 545 patentes depositadas. A Asahi Breweries é a empresa com mais patentes depositadas, conforme é possível ver na Figura 4. A terceira posição no ranking de patentes depositadas é ocupada pelos Estados Unidos com 421 patentes, sendo esse país o segundo maior produtor de cerveja no mundo e maior produtor de lúpulo. 
O Brasil encontra-se na oitava posição em termos de depósitos de patentes, mesmo possuindo a terceira maior produção de cerveja no mundo (LIMA et al., 2017). Segundo Fernandes et al. (2017), a posição do Brasil no ranking está relacionada a uma grande quantidade de tecnologias em caráter de segredo industrial, como é o caso da maior empresa brasileira do ramo cervejeiro, AmBev, do conglomerado AB InBev. Ou seja, tecnologias desenvolvidas internamente e que não foram depositadas na forma de patentes não têm como serem contabilizadas. O que ocorre também com a empresa alemã Baarth-Haas Group, a maior do ramo de comercialização de lúpulo, entretanto, com apenas uma única patente depositada.

A correlação entre mercado cervejeiro, produção de cerveja e depósito de patentes não informa diretamente quanto o país em questão investe em novas tecnologias no setor, dado que pode haver investimentos em regime de segredo industrial, não divulgados publicamente. A correlação se destaca como forte indicativo de que, apesar de as empresas desse nicho industrial não depositarem patentes, elas promovem inovação e desenvolvimento tecnológico, visto o aumento do número de produtos, a expansão das marcas e a diversificação da sua atuação comercial.

Figura 4 - Principais empresas depositantes no período de 2000 a 2019 com as palavras-chave ( $($ hop OR hops) AND beer) OR ((hop OR hops) AND (beverage OR drink)) e sem o inventor Kvasenkov Oleg Ivanovich

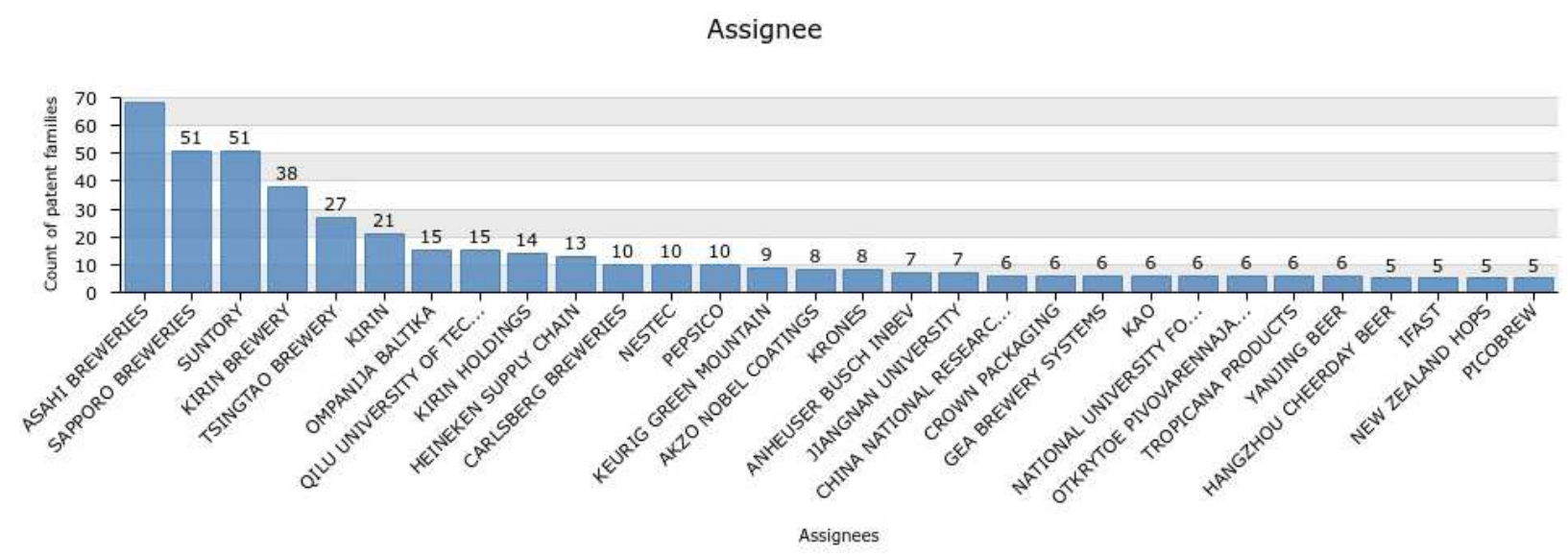

(c) Questel 2020

Fonte: Orbit (2020)

Quatro das cinco primeiras empresas com maior número de patentes depositadas são as japonesas Asahi Breweries (68), grupo Kirin (59), Sapporo Breweries (51) e Suntory (51) (Figura 4). Isso indica que os japoneses investem massivamente no desenvolvimento de novas tecnologias e na proteção por meio de patente nessa área. A relevância do Japão na área de propriedade intelectual se destaca não apenas nesse setor, mas também no ranking dos países que mais produzem patentes no mundo. Fernandes et al. (2017) justificam o grande número de empresas asiáticas no topo do ranking baseados em políticas de propriedade intelectual dos países do oriente aliadas à cultura de proteção bastante consolidada.

Entre as 30 empresas com maior número de depósitos, observou-se a presença de cervejarias de diversos países, centros de pesquisa chineses, a PepsiCo, o grupo AB InBev com apenas sete patentes e a empresa de lúpulos neozelandesa (New Zealand Hops). Mostrando que empresas 
de diferentes mercados na área de bebidas e alimentos se interessam e investem na criação de equipamentos, processos ou produtos de lúpulo.

Avaliando os domínios tecnológicos ligados à utilização de lúpulo no mercado de cervejas e bebidas, verificou-se uma concentração na área de química de alimentos, como esperado, mas também com bastante relevância nas áreas de biotecnologia, engenharia química, química orgânica fina, farmacêutica, química básica de materiais e de manuseamento, conforme mostra a Figura 5.

Figura 5 - Distribuição das patentes pela classificação CIP nas patentes distribuídas com as palavras-chave ((hop OR hops) AND beer) OR ((hop OR hops) AND (beverage OR drink))

\section{IPC citations}

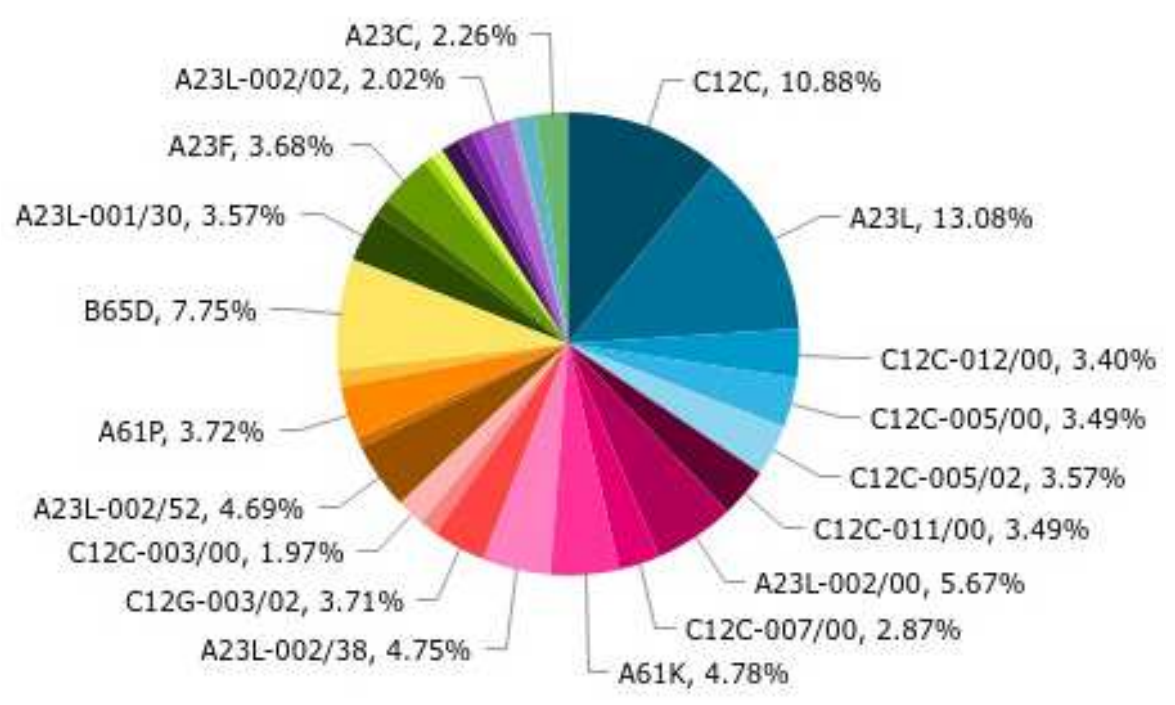

Fonte: Orbit (2020)

A Figura 5 traz a distribuição das patentes por meio da classificação CIP a partir das pesquisas com os termos "lúpulo e (bebidas ou cerveja)". Destaca-se a classificação A23L referente à produção bebidas não alcoólicas ou produtos alimentícios, sendo responsável por $37,74 \%$ das patentes encontradas. Contudo, a utilização da planta para produção de cerveja também tem parcela significativa, com $12,58 \%$. Mesmo com o aprimoramento da busca para o mercado cervejeiro, 9,69\% foram referentes ao uso terapêutico ou medicinal da planta, distribuída nas categorias A61K e A61P. Ainda estão representadas as CIPs: embalagens de armazenamento (B65D) com 8,66\%, entre outras categorias que juntas somam 31,33\% entre elas, equipamentos de cozinha (A47J com 6,72\%), química fina (C07D, 2,08\%), outras bebidas alcoólicas (C12G, 2,82\%) e infusão de lúpulo (A23F com 5,27\%) e laticínios (A23C, 2,56\%) e demais CIPs $(16,24 \%)$.

Com relação à prospecção científica, as palavras-chave (hop OR hops) resultaram em 73.968 artigos publicados (como apresentado na Tabela 1). Então, assim como para a busca por patentes, restringiu-se ao uso de lúpulo a bebidas (com os termos beer, beverage e drink), foram observados 1.140 artigos publicados envolvendo a utilização de lúpulo ou seus componentes relacionados a bebidas. 
A partir da distribuição de publicações científicas por país, como apresentado na Figura 6, observou-se que os Estados Unidos (214) e a Alemanha (185) são os países que mais possuem publicações, em concordância com o que se vê no mercado, em que esses países detêm a maior produção de lúpulo no mundo, sendo a maior empresa do ramo a alemã Barth-Haas Group. Ao analisar quais instituições são as que mais publicaram, verificou-se que a que mais publicou foi a Universidade Técnica de Munique, seguida pela estadunidense Universidade Estadual do Oregon. Segundo o Serviço Nacional de Estatísticas Agrícolas do Departamento de Agricultura dos EUA, os estados produtores, em ordem crescente, são: Oregon, Washington e Idaho, todos no extremo noroeste do país (EUA, 2018). O que significa que os centros de pesquisa na área estão em concordância com a necessidade local e de mercado. Ou seja, onde há maior cultivo e comercialização de lúpulo é onde ocorre a maior demanda de pesquisa e produção pelos centros de pesquisa. O terceiro com mais publicações é a empresa japonesa Asahi Breweries, revelando que a empresa investe no setor de pesquisa e desenvolvimento não apenas para patentes, mas também para pesquisas em geral.

Figura 6 - Número de artigos publicados levantados pelo sítio Web of Science nos anos de 2000 a 2019 pelos 25 países que mais publicam com as palavras-chave ((hop OR hops) AND beer) OR ((hop OR hops) AND (beverage OR drink))

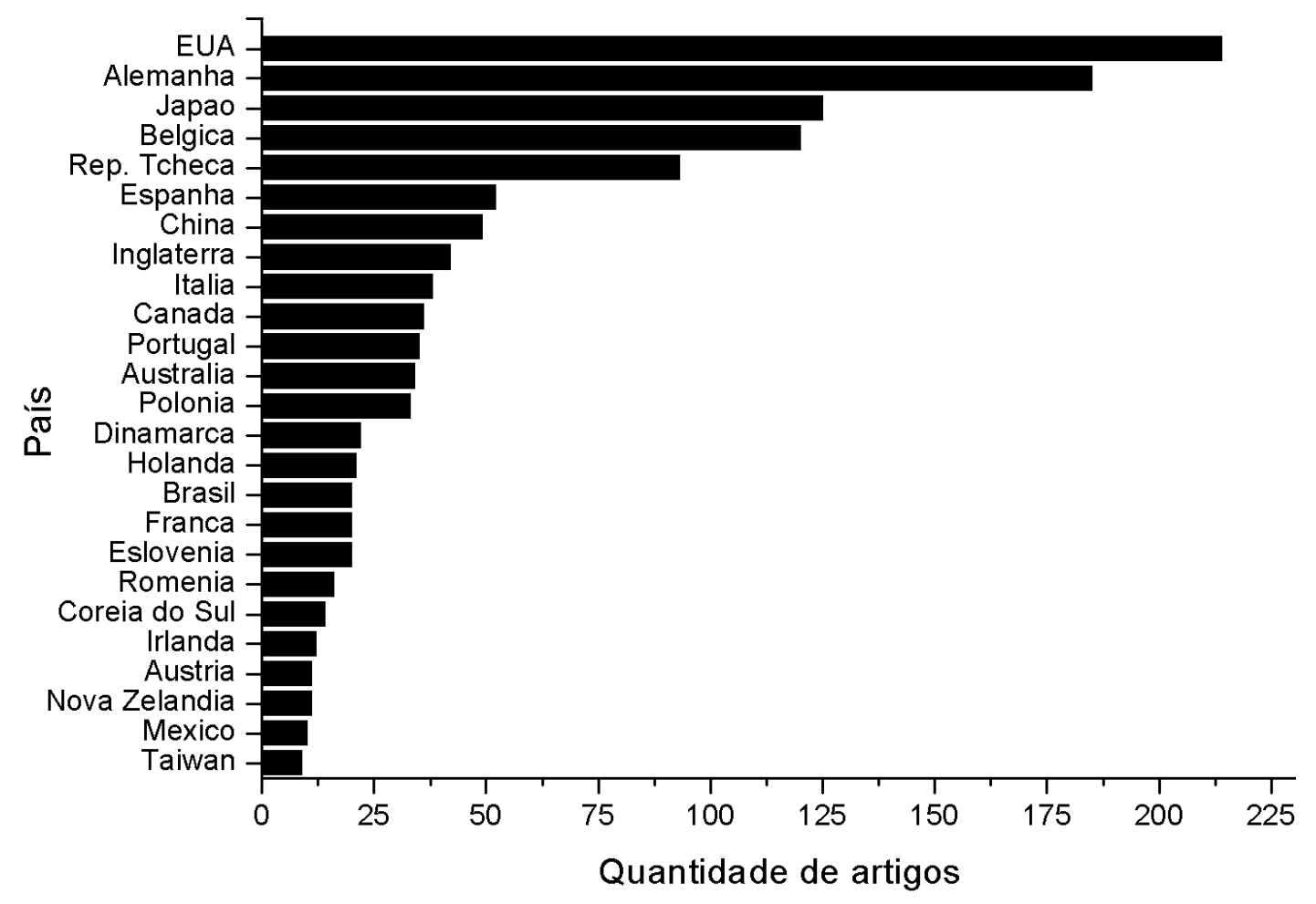

Fonte: Web of Science (2020)

Verificou-se que os países que mais têm produção acadêmica são os com maior indústria cervejeira ou de lúpulo. Os Estados Unidos ocupam o primeiro lugar em produção de cerveja e publicação de artigos na área pesquisada. A China, segundo lugar na produção de cerveja mundial, encontra-se em sexto lugar em quantidade de publicações (empatado com a Inglaterra). O Brasil, terceiro em produção, encontra-se na $16^{a}$ posição em termos de publicações. Esse prognóstico aponta novamente questões como regionalidade para a produção do lúpulo, mercado interno e consumo de cerveja, bem como incentivo e estabelecimento de empresas 
do setor. O Japão, país com grandes empresas no setor de cerveja, está na terceira posição dos países que mais publicam, podendo ser forte indicativo de um sistema que alia o setor industrial com a impulsão das pesquisas no setor.

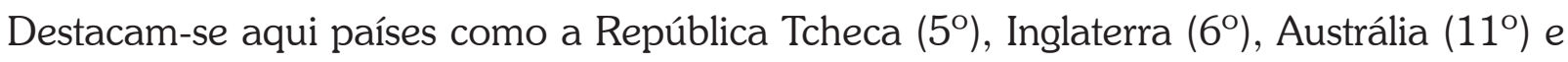
Nova Zelândia $\left(20^{\circ}\right)$ que possuem uma produção de lúpulo considerável, em especial para lúpulos exclusivos, estando ainda Austrália e Nova Zelândia como os maiores produtores do Hemisfério Sul. Destaca-se também a Bélgica $\left(4^{\circ}\right)$, que possui uma longa história cervejeira, não só pelas questões associadas a centros de pesquisa em cervejas, com uma escola cervejeira própria, conhecida pela utilização de adjuntos na fabricação de cervejas, mas também pela $A B$ InBev (empresa de capital belgo-brasileiro originado da junção da AmBev com a cervejaria belga Interbrew), uma das maiores do mercado (LIMA et al., 2017).

A fim de melhor comparar o crescimento de publicações científicas e de patentes, a Figura 7 traz um gráfico comparativo mostrando que ambas têm um crescimento proporcional $e$ contínuo ao longo dos anos, ainda que 2019 tenha tido uma queda no número de patentes. É interessante observar que por ser uma área de pesquisa inerentemente mercadológica, o número de patentes depositadas é superior ao de artigos em quase todos os anos. Observou-se, inclusive, que é muito comum aparecerem empresas do ramo na seção de agradecimentos dos artigos. Isso porque o desenvolvimento do conhecimento é de interesse mútuo da academia e de empresas, mostrando uma interação bastante produtiva para ambos os setores.

Figura 7 - Número de artigos publicados (em cinza) e de famílias de patentes depositadas (em vinho) nos anos de 2000 a 2019, utilizando as palavras-chave ((hop or hops) AND beer) OR ((hop or hops) AND (beverage OR drink)) em seu resumo, excluindo-se patentes do inventor Kvasenkov Oleg Ivanovich

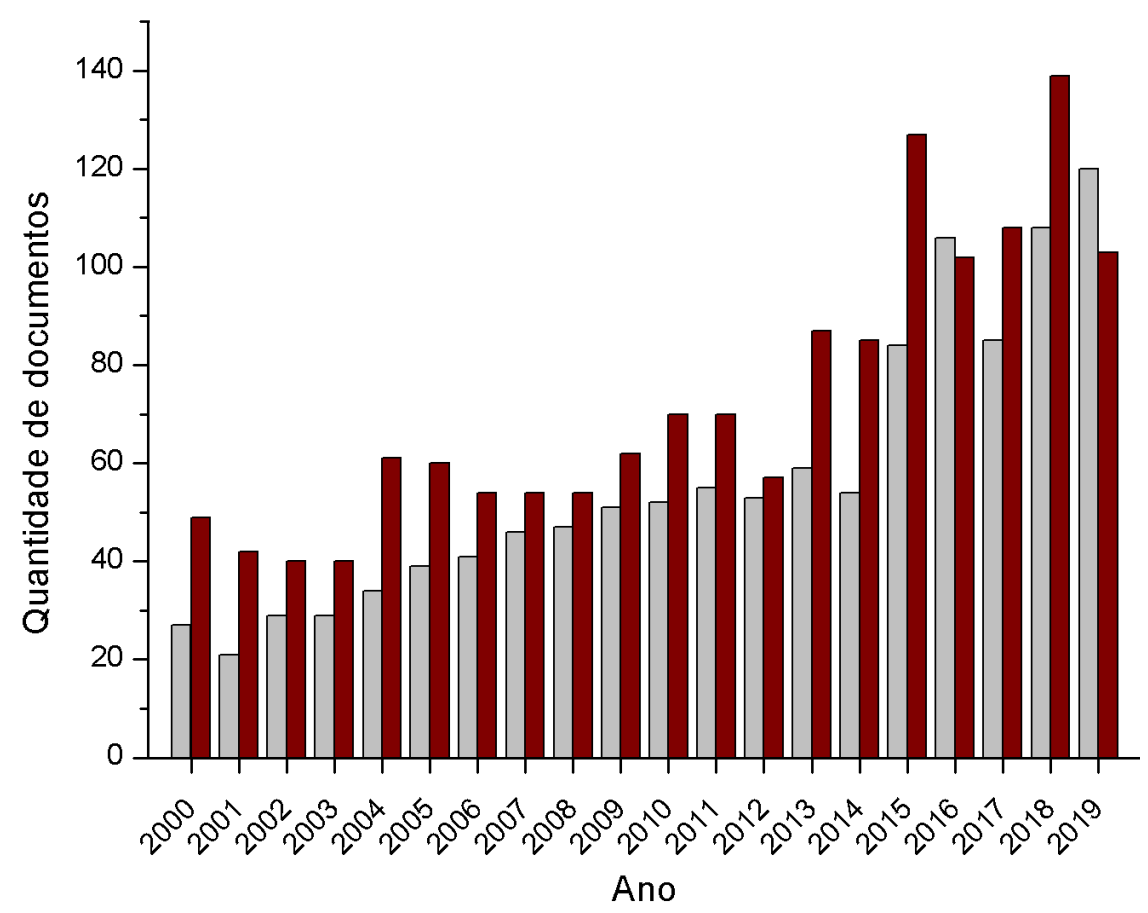

Fonte: Elaborada pelos autores deste artigo com dados de Web of Science (2020) e Orbit (2020) 


\subsection{Produção de Lúpulo no Brasil: espaço para novas tecnologias}

O Brasil iniciou recentemente o plantio de lúpulo com a adversidade de ser uma planta adaptada a um local de fotoperíodo maior, ou seja, dias com maior duração de incidência de raios solares. Com o crescimento das microcervejarias e do mercado cervejeiro como um todo, esse insumo poderá ser absorvido pelo mercado crescente, porém novas empresas de beneficiamento são requeridas a fim de melhorar o produto para sua utilização em maior escala.

Já há vários viveiros que fazem a comercialização de mudas da planta e possuem variedades adaptadas ao clima brasileiro). Diversos produtores familiares espalhados pelo Brasil iniciaram suas produções em pequena escala, pois muitos foram induzidos por cervejarias locais que querem produzir cervejas com insumos exclusivos de origem brasileira. O Ministério da Agricultura e Pecuária (MAPA) possibilita o registro de cultivares - nacionais ou importadas - mas ainda não criou diretrizes ou regulamentações sobre a cultura da planta. Há hoje 48 cultivares registrados (MAPA, 2020).

O crescimento no número de novas cervejarias no Brasil, em especial das micro e pequenas empresas é notório, o aumento é de $23 \%$ ao ano desde 2008 (BRASIL, 2018). Esse crescimento do número de cervejarias aumenta o consumo dos insumos para fabricação da bebida, em especial aquelas que se diferem das cervejas convencionais, como uso de madeira (GUIMARÃES, 2020) ou dry-hopping (adição de lúpulo na fermentação ou maturação da cerveja) (VOLLMER et al., 2018). Em especial o lúpulo, dado que um estilo muito produzido por micro e pequenas cervejarias é India Pale Ale, que utiliza muito lúpulo em sua fabricação. Esse aumento no consumo é um impulsionador para a produção interna de lúpulo, principalmente para abastecer essas cervejarias e proporcionar um menor preço de custo às suas cervejas, utilização de produto mais fresco, bem como um diferencial perante as outras, por possuir insumos locais ou nacionais. Além do mais, outros produtos já vêm sendo desenvolvidos, como a americana HOPS e a brasileira HOP, ambos utilizando água gaseificada com adição de lúpulo como saborizante. Demais produtos como chá, kombucha, entre outros, estão presentes no mercado.

Em maio de 2018, foi fundada a Associação de Produtores de Lúpulo (APROLÚPULO) juntamente com a Universidade do Estado de Santa Catarina (UDESC, 2018) com objetivo de gerar informações e fomentar a cultura do lúpulo. De acordo com a associação, há produtores de lúpulo nas Regiões Sul, Sudeste e Centro-Oeste, conforme indicado na Figura 8 (APROLÚPULO, 2020). A Região Sul do País é a que apresenta maior concentração de produtores de lúpulo (APROLÚPULO, 2020) e de cervejarias (BRASIL, 2018).

Além disso, a Região Sul é a que apresenta a maior variação na duração do dia ao longo do ano, o que favorece o crescimento da planta, adaptada a um fotoperíodo longo. Foi esse o motivo que incentivou o cultivo e, com base nos produtores que já tiveram resultados positivos e possibilidade de créditos agrícolas para a cultura, induziu outros produtores a plantarem e a estudarem sobre a cultura. De acordo com produtores associados à Aprolúpulo, a floração em território nacional é bianual, salvo o Distrito Federal em que a floração é trianual, ou seja, superior àquelas de países temperados em que só floresce uma vez ao ano. 
Figura 8 - Número de produtores de lúpulo associados por Estado

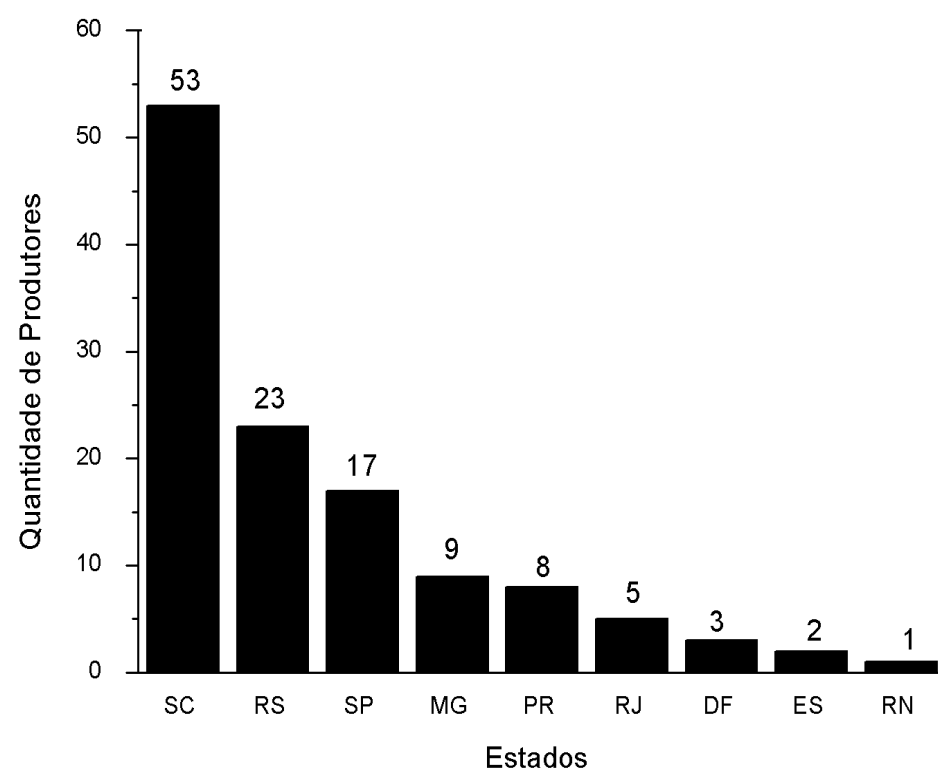

Fonte: Elaborada pelos autores deste artigo com dados de Aprolúpulo (2020)

Fazendo um paralelo entre a produção nacional e a dependência do mercado interno na importação dos produtos e derivados de lúpulo, fez-se uma análise a partir dos dados de importação e de exportação da Secretaria de Comércio Exterior do Brasil (MINISTÉRIO DA ECONOMIA, 2020) para os últimos 20 anos. Observou-se que o valor negociado de pellet está em ascensão, ainda que sua quantidade tenha se mantido relativamente constante até 2018 quando se verificou um aumento substancial do valor e na quantidade de lúpulo importado. $\mathrm{O}$ valor negociado em flor foi inferior a 60.000 dólares e suas quantidades foram inferiores a 11 toneladas, evidenciando a tendência do mercado de consumir principalmente o produto beneficiado. Observando essa tendência do mercado aliada ao crescimento de micro e pequenas cervejarias e aos altos gastos com importação (39 milhões de dólares em 2019), há a necessidade de mais incentivos a pesquisas, a políticas públicas e ao cultivo e beneficiamento da planta, a fim de poder melhor explorar o produto nacional. Alguns exemplos de incentivos foram o primeiro Encontro Brasileiro de Pesquisadores e Produtores de Lúpulo, o I ENBRALÚPULO, a possibilidade de registro de cultivares da planta no Mapa e a linha de crédito oferecida pelo Banco do Brasil a produtores do Estado do Rio de Janeiro. 
Figura 9 - Valores (a), em milhares de dólares, e quantidades (b), em toneladas, importadas (linha contínua, símbolos preenchidos) e exportadas (linha pontilhada, símbolos abertos) de flores de lúpulo in natura (estrela), lúpulo moído, em pó ou em pellet (círculo) e lupulina (triângulo) nos anos de 2000 a 2019
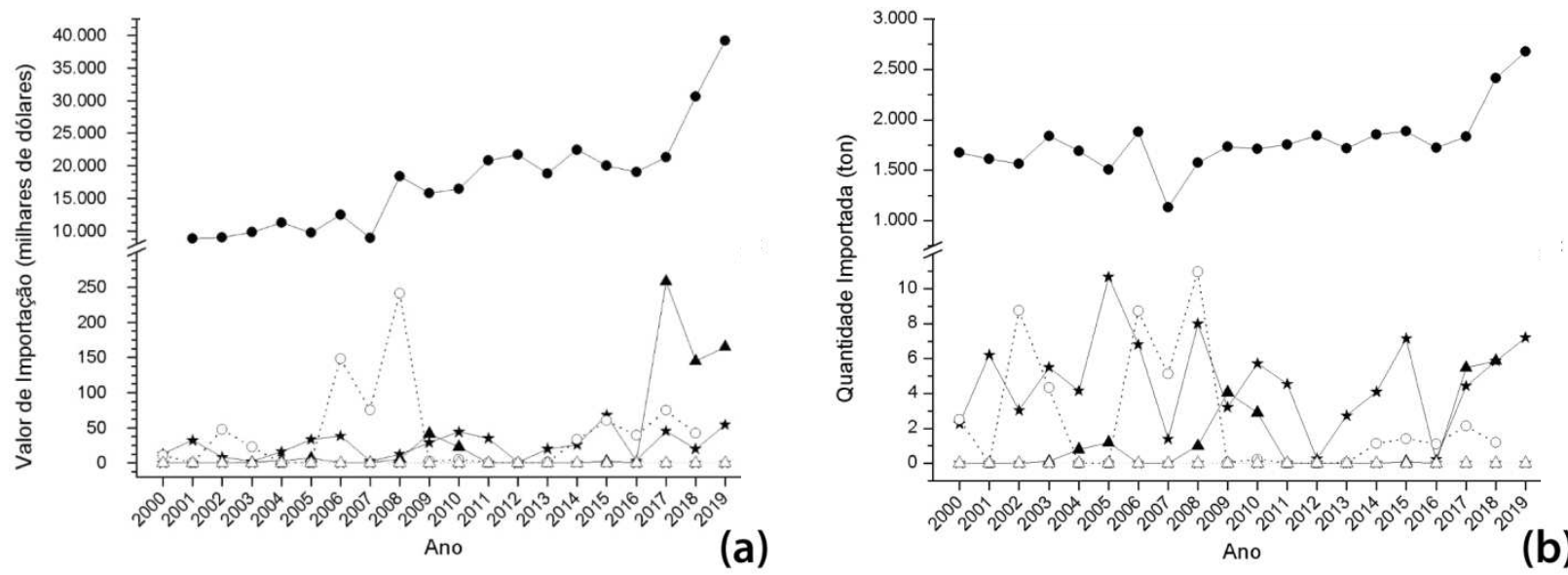

Fonte: Elaborada pelos autores deste artigo com dados do Ministério da Economia (2020)

Tomando como base o cenário atual, é possível vislumbrar cenários positivos ao cultivo de lúpulo e à manufatura. O mercado que mais consome lúpulo é o cervejeiro, que se encontra em amplo crescimento, ou seja, há espaço para a inclusão de produto nacional de menor custo. Além disso, com os estudos que estão sendo feitos em campo com os atuais produtores, observa-se a possibilidade de mais florações por ano. Enquanto na Alemanha e nos Estados Unidos a ocorrência de floração é uma vez ao ano, no Brasil já foram relatadas até três florações na Região Centro-Oeste. Esse número maior de florações, a possibilidade de ampliação de áreas de cultivo e lavouras aptas a produzirem a cultura, o incentivo e o apoio de instituições de ciência e tecnologia e financeiras fazem com que o Brasil possua um grande potencial de passar de importador a exportador de lúpulo nos próximos anos, como já ocorreu com outras culturas.

\section{Considerações Finais}

O universo cervejeiro é naturalmente mercadológico e evidenciado por uma produção acadêmica igual ou inferior ao número de patentes depositadas. Como o Brasil importa $98 \%$ do lúpulo utilizado na fabricação da bebida, um produto nacional não apenas aumentaria as riquezas nacionais, mas também impulsionaria diversos setores da economia. Para tanto, é necessário o desenvolvimento de conhecimento e de tecnologias nacionais, além de direcionamento governamental. Parcerias entre instituições de pesquisa e empresas do ramo podem alavancar o desenvolvimento de conhecimento e de tecnologias. Direcionamento governamental pode ser feito por meio de diretrizes quanto ao plantio, sua regulamentação pelo Mapa e políticas públicas para a cultura. 
Concluiu-se que o número de patentes e de publicações científicas aumentou nos últimos anos e que a academia e a indústria estão intimamente ligadas nessa área com vários artigos agradecendo ou tendo um de seus autores ligados à indústria cervejeira. As instituições com maior número de artigos foram a Universidade Estadual do Oregon (EUA) e a Universidade Técnica de Munique (Alemanha), ambas situadas nas maiores regiões de produção de lúpulo, mostrando um alinhamento entre produtores, pesquisadores e indústria. O Brasil, apesar de ser o terceiro produtor de cerveja, não se destaca como produtor de patentes e de artigos.

Destaca-se que o Brasil, ainda que esteja no início do cultivo da planta, apresenta grande potencial para ampliar sua produção e ser exportador no futuro, com área para cultivo $e$ relatos de múltiplas florações. Essas características aliadas a incentivos à pesquisa e ao cultivo faz com que o Brasil possa produzir e registrar cultivares nacionais com características únicas e melhores adaptados ao clima. A produção da planta, por sua vez, favorece o desenvolvimento de novas tecnologias e abre caminho para uma produção que supra a demanda interna. Isso poderia reduzir custos com importação, que atualmente são mais de 30 milhões de dólares, e desenvolver a indústria nacional. Com o aumento da produção, o Brasil poderá passar de importador a exportador de lúpulo.

\section{Referências}

APROLÚPULO - ASSOCIAÇÃO DE PRODUTORES DE LÚPULO. (Santa Catarina). Regiões Produtoras. 2020. Disponível em: http://aprolupulo.com.br/\#regiões. Acesso em: 20 ago. 2020.

BERBERT, Susana. Conheça a produção de lúpulo brasileiro. Globo Rural, 27 de fevereiro de 2017. Disponível em: https://revistagloborural.globo.com/Noticias/Agricultura/noticia/2017/02/ conheca-producao-de-lupulo-brasileiro.html. Acesso em: 23 jan. 2019.

BOCQUET, L. et al. Humulus lupulus L., a very popular beer ingredient and medicinal plant: overview of its phytochemistry, its bioactivity, and its biotechnology. Phytochemistry Reviews, [s.l.], v. 17, n. 5, p. 1.047-1.090, jul. 2018. Springer Nature America, Inc. DOI: https://doi.org.org/10.1007/ s11101-018-9584-y.

BRASIL. Carlos Vitor Müller e Eduardo Fernandes Marcusso. Divisão de Inspeção de Produtos de Origem Vegetal. Mapa Informa: as cervejarias continuam a crescer. Brasília, DF: Ministério da Agricultura, Pecuária e Abastecimento, 2018. 4 p. Disponível em: http://www.agricultura.gov.br/ assuntos/inspecao/produtos-vegetal/pasta-publicacoes-DIPOV/as-cervejas-continuam-a-crescer-pdf. pdf. Acesso em: 30 jan. 2019.

CARVALHO, Naiara Barbosa et al. Characterization of the consumer market and motivations for the consumption of craft beer. British Food Journal, [s.l.], v. 120, n. 2, p. 378-391, fev. 2018. Emerald. DOI: https://doi.org.org/10.1108/bfj-04-2017-0205.

CATTOOR, Ko et al. Metabolism of Hop-Derived Bitter Acids. Journal of Agricultural and Food Chemistry, [s.l.], v. 61, n. 33, p. 7.916-7.924, ago. 2013. American Chemical Society (ACS). http:// dx.doi.org/10.1021/jf300018s.

CLARIVATE ANALYTICS. (EUA). Source publication list for web of science: science citation index expanded. 2017. Disponível em: http://mjl.clarivate.com/publist_sciex.pdf. Acesso em: 31 jan. 2019. 
EUA - ESTADOS UNIDOS DA AMÉRICA. USDA - United States Department of Agriculture.

National Hop Report. Washington DC: National Agricultural Statistics Service, 2018. 6 p.

Disponível em: https://www.usahops.org/img/blog_pdf/158.pdf . Acesso em: 30 jan. 2019.

FERNANDES, Thiago Lara et al. Prospecção Tecnológica: uma Visão das Inovações e Perspectiva do Mercado Cervejeiro. Cadernos de Prospecção, Salvador, v. 10, n. 4, p. 580-595, dez. 2017. Universidade Federal da Bahia. DOI: https://dx.doi.org/10.9771/cp.v10i4.23039.

FREITAS, Carlos Felipe. Banco do Brasil abre linha de crédito de $\mathbf{R} \mathbf{6 0 0}$ milhões para cultivo de lúpulo no estado do Rio. 2019. Disponível em: https://catalisi.com.br/banco-do-brasil-abrelinha-de-credito-de-r-600-milhoes-para-cultivo-de-lupulo-no-estado-do-rio/. Acesso em 25 jul. 2019.

GUIMARÃES, Bernardo Pontes et al. Evaluation of maturation congeners in beer aged with Brazilian woods. Journal of Brewing and Distilling, [s.l.], v. 9, n. 1, p. 1-7, fev. 2020. Academic Journals.

IBGE - INSTITUTO BRASILEIRO DE GEOGRAFIA E ESTATÍSTICA. Pesquisa Industrial Anual - Produto. [2020]. Disponível em: sidra.ibge.gov.br/pesquisa/pia-produtos/quadros/brasil/2018. Acesso em: 20 ago. 2020.

IHGC - INTERNATIONAL HOP GROWERS' CONVENTION. (França). Economic Commission: Summary Reports. Paris: International Hop Growers' Convention, 2018. 55p. Disponível em: http:// www.hmelj-giz.si/ihgc/doc/2018\%20MAY\%20IHGC\%20EC\%20Reports.pdf. Acesso em: 29 jan. 2019.

LIMA, Larisse Araújo et al. Sinopse do Cenário Cervejeiro: o advento da produção e o mercado na Região Centro-Oeste. Cadernos de Prospecção, Salvador, v. 10, n. 4, p. 650-664, dez. 2017. Universidade Federal da Bahia. DOI: https://doi.org.org/10.9771/cp.v10i4.23041.

MAPA - MINISTÉRIO DA AGRICULTURA, PECUÁRIA E ABASTECIMENTO. Cultivarweb. [2020]. Disponível em: http://sistemas.agricultura.gov.br/snpc/cultivarweb/cultivares_registradas.php. Acesso em: 20 ago. 2020.

MARCUSSO, Eduardo Fernandes; MÜLLER, Carlos Vitor. A Economia e o Território do Lúpulo: a história, análise mercadológica e o desenvolvimento do lúpulo no Brasil e no mundo. Revista Latino-Americana da Cerveja, Blumenau, v. 2, n. 2, p. 1-20, 2019. Faculdade Épica.

MINISTÉRIO DA ECONOMIA. Comex Stat - Exportação e Importação Geral. [2020].

Disponível em: http://comexstat.mdic.gov.br/pt/geral. Acesso em: 20 ago. 2020.

OLIVEIRA, Lincoln et al. Prospecção tecnológica da utilização de catalisadores sólidos ácidos carbonáceos produzidos por meio de tratamento termoquímico. Cadernos de Prospecção, Salvador, v. 11, n. 4, p. 1136-1149, dez. 2018. Universidade Federal da Bahia. DOI: https://doi.org. org/10.9771/cp.v11i4.27182

ORBIT [Base de dados - Internet]. Questel Orbit Intelligence. [2020]. Disponível em: https:/www. orbit.com. Acesso em 20 ago. 2020.

UDESC - UNIVERSIDADE DO ESTADO DE SANTA CATARINA. Produtores de lúpulo criam associação brasileira com sede na UDESC Lages. 2018. Disponível em: https:/www.udesc.br/ noticia/produtores_de_lupulo_criam_associacao_brasileira_com_sede_na_udesc_lages. Acesso em: 31 jan. 2019.

VOLLMER, Daniel et al. Aroma extract dilution analysis of beers dry-hopped with Cascade, Chinook, and Centennial. Journal of the American Society of Brewing Chemists, [s.l.], v. 76, p. 190-198, set. 2018. DOI: https://doi.org.org/10.1080/03610470.2018.1487746. 
WEB OF SCIENCE. [Base de dados - Internet]. Coleção Principal (Thomson Reuters

Scientific). [2020]. Disponível em: http://apps-webofknowledge.ez54.periodicos.capes.gov.br/WOS GeneralSearch_input.do?product=WOS\&search_mode $=$ GeneralSearch\&SID $=1$ B5tqQhpLFnGGdto 2AI\&preferencesSaved $=$. Acesso em: 20 ago. $20 \overline{2} 0$.

YAN, DanDan et al. Assessment of the phytochemical profiles of novel hop (Humulus lupulus L.) cultivars: A potential route to beer crafting. Food Chemistry, [s.l.], v. 275, p. 15-23, set. 2018. Elsevier BV. DOI: https://doi.org.org/10.1016/j.foodchem.2018.09.082.

\section{Sobre os Autores}

\section{Bernardo Pontes Guimarães}

E-mail: bepontesgui@gmail.com

ORCID: http://orcid.org/0000-0002-8215-7495

Bacharel em Química.

Endereço profissional: Laboratório de Bioprocessos Cervejeiros e Catálise em Energias Renováveis (LaBCCERva), B1- 75/3, Instituto de Química, Universidade de Brasília, Campus Darcy Ribeiro, Asa Norte, Brasília, DF. CEP: 70910-900.

\section{Rafael Benjamin Werneburg Evaristo}

E-mail: rafael.werneburg@gmail.com

ORCID: http://orcid.org/0000-0002-9742-3522

Mestre em Química.

Endereço profissional: Laboratório de Bioprocessos Cervejeiros e Catálise em Energias Renováveis (LaBCCERva), B1- 75/3, Instituto de Química, Universidade de Brasília, Campus Darcy Ribeiro, Asa Norte, Brasília, DF. CEP: 70910-900.

\section{Grace Ferreira Ghesti}

E-mail: grace@unb.br

ORCID: http://orcid.org/0000-0003-1043-5748

Doutora em Química.

Endereço profissional: Laboratório de Bioprocessos Cervejeiros e Catálise em Energias Renováveis (LaBCCERva), B1- 75/3, Instituto de Química, Universidade de Brasília, Campus Darcy Ribeiro, Asa Norte, Brasília, DF. CEP: 70910-900. 